\title{
Executive cognitive dysfunction and ADHD in cocaine dependence: searching for a common cognitive endophenotype for addictive disorders
}

\author{
Paulo Jannuzzi Cunha ${ }^{1,2,3,4}$ *, Priscila Dib Gonçalves ${ }^{1,2,3}$, Mariella Ometto ${ }^{1,2,4}$, Bernardo dos Santos ${ }^{5}$, \\ Sergio Nicastri ${ }^{1,2,3}$, Geraldo F. Busatto ${ }^{1,2}$ and Arthur Guerra de Andrade ${ }^{3}$ \\ 1 Laboratory of Psychiatric Neuroimaging (LIM-21), Department of Psychiatry, Faculty of Medicine, University of São Paulo (USP), São Paulo, SP, Brazil \\ ${ }^{2}$ Center for Interdisciplinary Research on Applied Neurosciences (NAPNA), USP, São Paulo, SP, Brazil \\ ${ }^{3}$ Interdisciplinary Group of Studies on Alcohol and Drugs (GREA), Faculty of Medicine, USP, São Paulo, SP, Brazil \\ ${ }^{4}$ Equilibrium Program, Department of Psychiatry, Faculty of Medicine, USP, São Paulo, SP, Brazil \\ ${ }^{5}$ School of Nursing, USP, São Paulo, SP, Brazil
}

\section{Edited by:}

Antonio Verdejo-García, Universidad de Granada, Spain

Reviewed by:

Giovanni Martinotti, Catholic University of Rome, Italy

Otto Lesch, Medical University of

Vienna, Austria

${ }^{*}$ Correspondence:

Paulo Jannuzzi Cunha, Laboratory of Neuroimaging (LIM-21), Department and Institute of Psychiatry, Center for Interdisciplinary Research on Applied Neurosciences (NAPNA), University of São Paulo (USP), Rua Capote Valente, 439, Conj. 64, J. América, São Paulo, SP 05409-001, Brazil e-mail: pjcunha@usp.br
Background: Cocaine-dependent individuals (CDI) present executive cognitive function (ECF) deficits, but the impact of psychiatric comorbidities such as Attention-Deficit Hyperactivity Disorder (ADHD) on neuropsychological functioning is still poorly understood. The aim of this study was to investigate if $C D I$ with ADHD (CDI + ADHD) would have a distinct pattern of executive functioning when compared with CDI without ADHD (CDI).

Methods: We evaluated 101 adults, including 69 cocaine-dependent subjects (divided in $\mathrm{CDI}$ and $\mathrm{CDI}+\mathrm{ADHD}$ ) and 32 controls. ECF domains were assessed with Digits Forward (DF), Digits Backward (DB), Stroop Color Word Test (SCWT), the Wisconsin Card Sorting Test (WCST), and the Frontal Assessment Battery (FAB). DSM-IV criteria for ADHD were used for diagnosis and previous ADHD symptoms (in the childhood) were retrospectively assessed by the Wender-Utah Rating Scale (WURS).

Results: There were no significant differences between CDI + ADHD, CDI, and controls in estimated intellectual quotient (IQ), socioeconomic background, education (in years), and pre-morbid IQ ( $p>0.05)$. SCWT and WCST scores did not differ across groups $(p>0.05)$. Nevertheless, $\mathrm{CDI}$ and $\mathrm{CDI}+\mathrm{ADHD}$ performed more poorly than controls in total score of the FAB $(p<0.05)$. Also, $\mathrm{CDI}+\mathrm{ADHD}$ did worse than $\mathrm{CDI}$ on $\mathrm{DF}(F=4.756, p=0.011)$, DB $(F=8.037, p=0.001)$, Conceptualization/FAB $(F=4.635, p=0.012)$, and Mental flexibility/FAB ( $F=3.678, p=0.029)$. We did not find correlations between cocaine-use variables and neuropsychological functioning, but previous ADHD symptoms assessed by WURS were negatively associated with DF $(p=0.016)$ and with the total score of the FAB $(p=0.017)$.

Conclusion: $\mathrm{CDI}+\mathrm{ADHD}$ presented more pronounced executive alterations than $\mathrm{CDI}$ and $\mathrm{CDI}$ exhibited poorer cognitive functioning than controls. Pre-existing ADHD symptoms may have a significant negative impact on executive dysfunction in CDI. It remains to be investigated by future studies if symptoms such as impulsivity or a pre-existing ECF dysfunction could represent underlying cognitive endophenotypes that would substantially increase the risk for acquiring addictive disorders.

Keywords: executive dysfunction, ADHD, cocaine, addiction, impulsivity, prefrontal cortex

\section{INTRODUCTION}

There is accumulating evidence from cognitive neuroscience research that cocaine-dependent individuals (CDI) present prefrontal cortex (PFC) functional and structural abnormalities (15), which are associated with executive cognitive function (ECF) deficits (6-8). Data suggest that regional metabolic alterations seen in $\mathrm{CDI}$ are associated with changes in brain dopamine activity $(2,9,10)$ as well as with neuronal injury in the frontal cortex in both frontal gray and white matter $(5,11-13)$. There are also several studies showing that chronic cocaine-use is associated with attention, memory, and executive impairments (7, 14-19).

Our research group has shown that cocaine-use is associated with hypoperfusion in several areas of the brain (3) and that CDI present several cognitive impairments which have real-life implications (16-18). We have recently evaluated $30 \mathrm{CDI}$, after 2 weeks of abstinence, and compared with 32 healthy individuals in frontal executive tasks. CDI performed more poorly than controls in digits forward (DF), digits backward (DB), and on the 
Frontal Assessment Battery (FAB) (17). The FAB is a brief neuropsychological battery devised by neurologists, composed of six subtests which evaluate different ECF-related functions (20). The performance on the six subtests of the FAB gives a global score suggesting a "descriptive pattern of ECF in a given patient" (20). In our study, CDI were cognitively impaired in 50\% (3/6) of the cognitive domains assessed by the FAB: abstract reasoning, motor planning, and cognitive flexibility. The results on the FAB were correlated with traditional frontal/executive tasks, showing that the FAB is a good indicator of severity of the executive dysfunction in CDI. Another recent study from our group aimed to investigate a possible link between ECF-related tasks and what happens in the real social life of CDI. The results indicated that impaired ECF in CDI was correlated with their higher levels of social dysfunction, in several areas of the social domain, including work, leisure, family, and finances (18). The relevance of executive dysfunction in CDI is also justified because ECF-related impairments are associated with poor treatment retention in cognitive-behavioral therapy (CBT) $(21,22)$ and with relapses $(23)$.

However, it is difficult to determine to what extent the substance per se leads to ECF alterations through its influence on brain functioning, or if the ECF deficits would represent pre-morbid factors which may lead to stimulant dependence (5) and to more intense neuropsychological deficits. According to recent studies, ECF impairments may be both predisposing factors and/or negative consequences of CDI (17,24-27). Fillmore and Rush (27) have argued that a common cognitive characteristic of CDI is an executive deficit, which makes them more vulnerable to risky behaviors and substance abuse. Animal studies also reinforce the hypothesis that a impaired self-control, impulsivity, and ECF alterations may be candidates neurocognitive endophenotypes that predates the emergence of addictions (28-30); those symptoms are very common across disorders such as Attention-Deficit Hyperactivity Disorder (ADHD) $(5,30)$.

Attention-deficit hyperactivity disorder is characterized as a neuropsychiatric disorder, with inattention, hyperactivity, and impulsivity symptoms (31). ADHD is significantly more prevalent among CDI than in the general population (32). The high prevalence of $\mathrm{ADHD}$ among $\mathrm{CDI}$ could be a significant confounding factor for neuropsychological studies, as ADHD per se is associated with neuropsychological deficits that affect predominantly ECF and also interfere in daily life activities (33-35). The ADHD cognitive endophenotype includes deficits in response inhibition that leads to impulsivity $(30,36)$, and this is considered a possible vulnerability marker for cocaine dependence (27). Moreover, it has been suggested that measures of response inhibition can help identify genetic susceptibility to ADHD (36).

However, there is not enough evidence to establish if the ECF deficits are pre-existing factors in CDI, which could lead to reallife problems and then make the subject more vulnerable to drug addiction, or if the cocaine-use per se would be the main factor that impairs ECF leading to the persistence of cocaine-use despite negative consequences (18). We consider that there is still inconsistency regarding the findings of attention and executive deficits among CDI, due to different methodologies applied and to the lack of more controlled studies (37). Further studies are necessary to verify the nature and severity of the attention and executive deficits associated with cocaine-use, as they have a direct clinical implication in treatment $(6,7,16,32)$. To date, few studies have investigated the role of ADHD in cocaine dependence. One study showed that although cocaine abusers performed significantly more poorly than controls on several neuropsychological tasks, there was no significant relationship between measures of childhood ADHD symptoms and neuropsychological performance (38). On the other hand, more recently, it was observed that ADHD symptoms were important modulators of cognitive function in $\mathrm{CDI}$, suggesting that cocaine-use and ADHD symptoms seem to have mutual aggravating effects in executive impairments (19).

Considering that there are still controversies about the role of ADHD diagnosis in cognitive performance of CDI, our aim was to evaluate the ECF deficits among CDI and to investigate the impact of an ADHD diagnosis on these patients. Our hypothesis was that $\mathrm{CDI}$ with $\mathrm{ADHD}$ diagnosis would present more pronounced deficits on ECF and that ADHD symptoms and cocaine-userelated variables such as age at onset would be correlated with the degree of ECF deficits in these patients.

\section{MATERIALS AND METHODS PARTICIPANTS}

Hundred and one subjects participated in this study. All the CDI (with or without ADHD, $n=69$ ) met the DSM-IV-TR criteria (31) for cocaine dependence at the time of admission to the treatment program. The CDI were recruited from two inpatient units: (1) the Interdisciplinary Group of Studies on Alcohol and Drugs (GREA) at the University of São Paulo (USP); (2) the Association for the Promotion of Prayer and Work (APOT) in Campinas (SP, Brazil). Exclusion criteria included were: (1) past or current major DSM diagnosis of psychotic disorders, or a current diagnosis of bipolar disorders; (2) met DSM criteria for opioid dependence; (3) had a history of neurological condition such as epilepsy and/or head injuries with loss of consciousness for longer than $30 \mathrm{~min}$, strokes and intracranial hemorrhages; (4) had prior diagnosis of learning disorder; (5) had intellectual quotient (IQ) less than 70. The CDI were all treatment-seeking cocaine-dependent patients evaluated after at least 1 week of abstinence. The abstinence was verified by self-report and supervised by the clinical staff of the inpatient units. For the majority of these patients $(n=39,56.5 \%)$, two urine tests were used to verify recent cocaine-use (if positive) and after to verify their abstinence (if negative), since recent cocaine-use may mask cognitive impairments in CDI (39). The neurocognitive performance of the CDI was compared to a control group which consisted of 32 healthy individuals, who were volunteers, recruited in the city of São Paulo. The control group consisted of employes from the public hospital where the research center (GREA) is located $(n=2)$ and the local police department $(n=12)$. We also recruited adult students from a public school $(n=18)$. The transport costs of the volunteers were reimbursed. The exclusion criteria for the control group were: (1) met DSM criteria for any psychoactive substance dependence other than nicotine; (2) the same exclusion criteria of the cocaine group.

\section{PROCEDURES AND ETHICAL CONSIDERATIONS}

The data presented in this report were collected between January 2001 and March 2013. The research protocol satisfied the 
Helsinki Declaration and was approved by the University of Sao Paulo Review Board (CAPPesq). After signing an informed consent, participants were interviewed by either a clinical psychologist or a psychiatrist. The interview questions covered demographics, drug use, and the consequences of drug use on their psychosocial functioning. Investigators obtained initial demographic and clinical information by a semi-structured interview used by neuropsychologists at our research center (17). The semi-structured neuropsychological interview included basic information such as name, address, gender, age, ethnic, handedness, educational background, professional activities, socioeconomic level, as well as questions about the medical past and current history, neurodevelopmental history, and neurocognitive complaints associated with cocaine and drug use $(16,18)$.

\section{MOOD, ANXIETY, AND DRUG USE EVALUATION}

Psychological and psychiatric symptoms were assessed by the Beck Depression Inventory (BDI) (40) and the State-Trait Anxiety Inventory (STAI) (41). Alcohol, tobacco, and other drug use, as well as the consequences of drug use among the cocaine group, were assessed using the Cocaine Addiction Severity Test (CAST) and Cocaine Assessment Profile (42) or the ASI-6 Addiction Severity Index (43).

\section{NEUROPSYCHOLOGICAL MEASURES \\ Digits forward and backward, from the revised version of the Wechsler Adult Intelligence Scale}

Digits forward was used was used to measure attention span and DB working memory (44). In DF the examinee needs to repeat a sequence of random numbers in the same order and DB in the reverse order (45).

\section{Stroop color word test}

It was designed to measure selective attention, cognitive flexibility, and inhibitory control $(45,46)$. Here it was used a Stroop color word test (SCWT) Portuguese version, published elsewhere (17).

\section{Wisconsin card sorting test}

The 64 card version $(47,48)$, translated and validated for use in Brazil $(17,49)$. This task evaluates ECF such as: mental flexibility, abstract reasoning, capacity to maintain the cognitive setting and self-monitoring (45).

\section{Frontal assessment battery}

The administration of the FAB takes approximately 10 min; each subtest is scored from 0 (minimum score) to 3 (maximum score) and the total score of the FAB is the sum of the scores in the six subtests (the FAB's total score ranges from 0 to 18) (20). The FAB was translated into Portuguese $(17,50)$ and detailed information about instructions of the FAB are described elsewhere (20). The six subtests are: conceptualization, mental flexibility, motor programing, sensitivity to interference, inhibitory control, and environmental autonomy.

\section{Intellectual functioning}

We used short forms of the Wechsler Intelligence Scale for Adults - Revised [WAIS-R, (44)] and the Wechsler Adult Scale of
Intelligence (WASI) to evaluate an estimated IQ which is a reliable measure of Full Scale IQ.

\section{OBJECTIVE MEASUREMENT OF ADHD SYMPTOMS AND DIAGNOSIS Wender-Utah rating scale}

It evaluates retrospectively different symptoms of ADHD. Here we used an abbreviated version of the Wender-Utah Rating Scale (WURS) comprising 25 of the 61 items from the original scale, which has shown to better discriminate between patients with ADHD and a non-patient comparison group (51). Participants were asked to self-report if they had experienced those ADHD symptoms during the childhood (until the age of 12 years old) on a Likert-type scale scored 0 (not at all or very slightly), 1 (mildly), 2 (moderately), 3 (quite a bit), and 4 (very much). The WURS minimum score is 0 and the maximum score is 100 . The total was calculated and participants were considered as having preexistent ADHD significant symptoms if they scored 46 or above, which has shown to be a reliable estimate for ADHD diagnosis in the childhood. More specifically, in a validation study, a cutoff score of 46 or higher correctly identified $86 \%$ of the patients with ADHD and $99 \%$ of the normal subjects (51).

\section{ADHD diagnosis by DSM-IV-TR}

It is based in nine symptoms of Inattention and nine symptoms of Hyperactivity/Impulsivity (31). The patient must fulfill at least six of nine (six or more) symptoms in each group or in both groups (Inattention and Hyperactivity/Impulsivity). The symptoms must have persisted for at least 6 months to a degree that is inconsistent with developmental level and that impact directly on social and academic/occupational activities. A requirement for the diagnosis of ADHD in adults is a childhood history of ADHD which was measured by WURS (right above).

\section{Definition of CDI+ ADHD, CDI, and controls}

We only considered subjects in the group called CDI + ADHD if they had fulfilled both confirmation of the adult ADHD diagnosis by DSM-IV-TR criteria (31) and if they had a WURS total score of 46 or higher (51).

\section{STATISTICAL ANALYSES}

Differences in performance on neuropsychological tests were assessed with unpaired $t$-tests and categorical variables were evaluated using Fisher's exact test. The normal distribution of each cognitive variable was confirmed by the Kolmogorov-Smirnov test. The level of statistical significance was $\alpha=0.05$ and all statistical tests were two tailed. Comparative analysis considering three groups (CDI, CDI + ADHD, and controls) was made using Analysis of Variance (ANOVA) and Bonferroni post hoc testing. Additionally, between-group analysis of cognitive functioning was conducted using Analysis of Covariance (ANCOVA) with age and gender as covariates. Correlation between neuropsychological measures [i.e., DF, DB, SCWT, Wisconsin Card Sorting Test (WCST), and FAB], cocaine-use variables (i.e., age at onset, abstinence, and duration of cocaine-use), and WURS (total score) was assessed by the Spearman correlation coefficient $\left(r_{\mathrm{s}}\right)$. All statistical analyses were conducted using Statistical Package for the Social Science (SPSS) software version 14.0 for Windows. 
Table 1 | Socio-demographic variables, intellectual functioning, and substance use of the CDI, CDI + ADHD, and healthy controls.

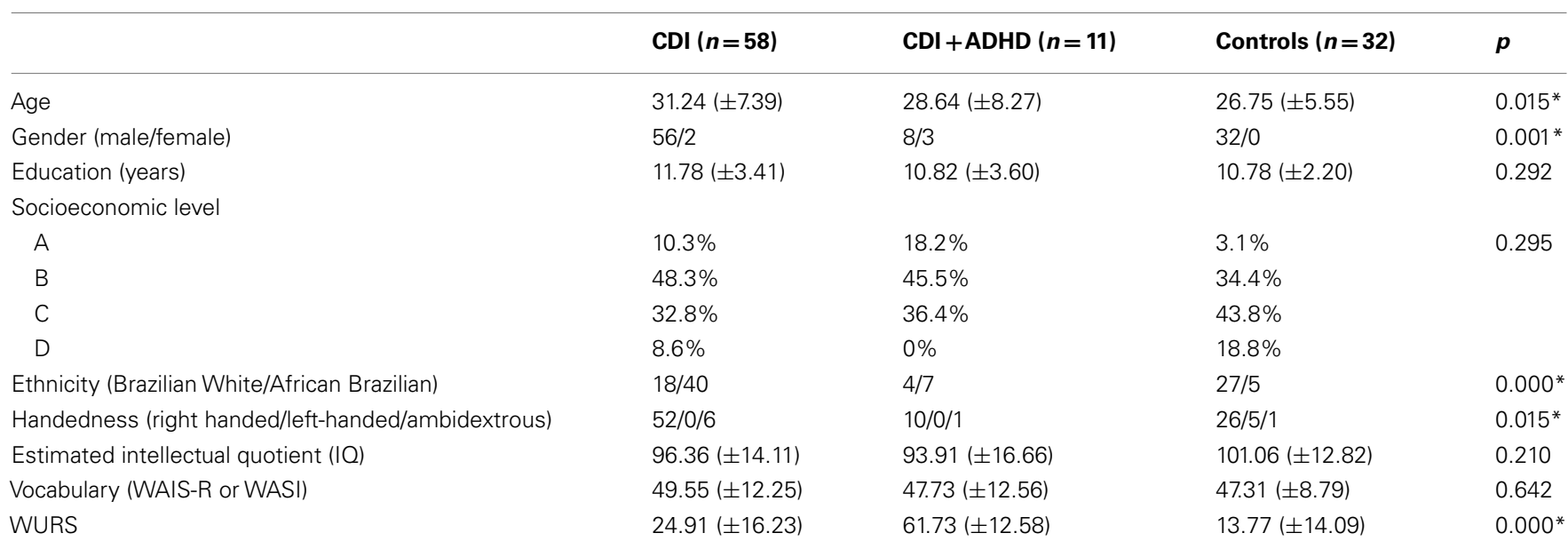

$C D I$, cocaine-dependent individuals; CDI+ADHD, cocaine-dependent individuals with attention deficit/hyperactivity disorder; SD, Standard Deviation ( \pm ); WAIS-R, Wechsler Adult Intelligence Scale-Revised; WASI, Wechsler Abbreviated Scale of Intelligence; WURS, Wender-Utah Rating Scale; Quantitative variables were compared using ANOVA and categorical variables were compared using Pearson Chi-Square; ${ }^{*} p<0.05$ - statistically significant. Socioeconomic levels were classified according to Brazilian norms (ABIPEME): $A=$ highest socioeconomic level and $D=$ lowest socioeconomic level.

\section{RESULTS}

\section{DEMOGRAPHIC AND CLINICAL CHARACTERISTICS}

Socio-demographic and some clinical characteristics of the groups are described in Table 1.

The three groups did not differ in educational level (in years), socioeconomic level, estimated IQ, and vocabulary score. However we found differences among groups regarding age, gender, ethnicity, handedness, and childhood ADHD scores (WURS). Controls were younger, male, more frequently white, and left-handed, in comparison to both CDI + ADHD $(n=11)$ and CDI $(n=58)$. CDI + ADHD had significantly higher WURS scores, followed by CDI and normal controls (Table 1).

\section{COCAINE, ALCOHOL, AND OTHER SUBSTANCE RECENT USE BY THE CDI AND CDI + ADHD}

Groups with a history of cocaine dependence (CDI and $\mathrm{CDI}+\mathrm{ADHD}$ ) did not differ significantly in terms of the main cocaine-use variables, such as age at onset, duration (in years), and length of abstinence (Table 2). They also showed a similar pattern of recent use for other substances, such as alcohol, cannabis, tobacco, heroin, amphetamine, sedatives, and LSD. Differences were only detected for alcohol and tobacco recent use when comparing both groups of patients (CDI and CDI $=$ ADHD) with controls. There were no differences between the percentages of cannabis and multiple substance abusers among the groups of patients.

\section{NEUROPSYCHOLOGICAL FINDINGS}

The ANOVA including the three groups (CDI, CDI + ADHD, and controls) did not show any statistically significant difference among patients and controls in all measures of SCWT and WCST. However, groups differed in attention (DF: $F=4.756, p=0.011$ ) and in working memory (DB: $F=8.037, p=0.001$ ) tasks (Table 3). Post hoc comparisons
Table 2 | Cocaine, alcohol, and other drug use in the CDI and CDI + ADHD.

\begin{tabular}{lllll}
\hline & CDI $(\boldsymbol{n}=\mathbf{5 8})$ & $\begin{array}{l}\text { CDI + ADHD } \\
(\boldsymbol{n}=\mathbf{1 1})\end{array}$ & $\begin{array}{l}\text { Controls } \\
(\boldsymbol{n}=\mathbf{3 2})\end{array}$ & $\boldsymbol{p}$ \\
\hline COCAINE-USE & & & & \\
Age at onset & $18.81 \pm 4.57$ & $18.27 \pm 6.42$ & - & 0.739 \\
Duration (years) & $10.71 \pm 6.98$ & $8.27 \pm 4.38$ & - & 0.270 \\
Abstinence (days) & $12.40 \pm 9.16$ & $12.09 \pm 4.30$ & - & 0.914 \\
ALCOHOL AND OTHER SUBSTANCES & (RECENT USE, $\boldsymbol{n})$ & \\
Alcohol & $53.4 \%$ & $45.5 \%$ & $9.4 \%$ & 0.000 \\
Tobacco & $69 \%$ & $81.8 \%$ & $12.5 \%$ & 0.000 \\
Cannabis & $39.7 \%$ & $54.5 \%$ & - & 0.278 \\
Heroin & $1.7 \%$ & $0 \%$ & - & 1.000 \\
Amphetamine & $1.7 \%$ & $0 \%$ & - & 1.000 \\
Sedatives & $20.7 \%$ & $27.3 \%$ & - & 0.694 \\
Multiple substance users & $27.3 \%$ & $27.6 \%$ & - & 1.000
\end{tabular}

$C D I$, cocaine-dependent individuals; $C D I+A D H D$, cocaine-dependent individuals with attention deficit/hyperactivity disorder; Recent use=was defined as substance use for at least three times a week in the last 30 days; Quantitative variables (about cocaine-use) were compared using Student t-test for comparisons among $C D I$ and $C D I+A D H D$; Categorical variables labout alcohol and other substances) were compared using Pearson Chi-Square and Fisher's Exact Test; ${ }^{*} p<0.05$ - statistically significant; $p$ refers to comparative analyses only between $C D I$ and $C D I+A D H D$ except for alcohol and tobacco recent use $(C D) \times C D I+A D H D \times$ Controls $)$.

showed that the difference in DF was due to worse performance of CDI + ADHD in comparison to both CDI $(p=0.013)$ and controls $(p=0.011)$. CDI did not differ significantly from controls in this task (DF). Differences in the test of working memory (DB) were due to a lowered performance of both groups of cocaine-dependents (CDI + ADHD and CDI) when directly and separately compared with 
Table 3 | Performance of CDI, CDI + ADHD, and healthy controls in traditional neuropsychological tests designed to evaluate executive cognitive functioning (ECF).

\begin{tabular}{|c|c|c|c|c|c|c|}
\hline $\begin{array}{l}\text { Neurocognitive } \\
\text { functions }\end{array}$ & \multicolumn{2}{|c|}{ Neuropsychological tests } & \multirow{2}{*}{$\begin{array}{l}\text { CDI mean }( \pm \text { SD }) \\
(\boldsymbol{n}=\mathbf{5 8}) \\
14.460 \pm 3.63\end{array}$} & \multirow{2}{*}{$\begin{array}{l}\text { CDI }+ \text { ADHD mean }( \pm \mathbf{S D}) \\
(\boldsymbol{n}=\mathbf{1 1}) \\
13.745 \pm 2.31\end{array}$} & \multirow{2}{*}{$\begin{array}{l}\text { Controls mean }( \pm \mathbf{S D}) \\
(\boldsymbol{n = 3 2 )} \\
\qquad 14.58 \pm 4.22\end{array}$} & \multirow{2}{*}{$\begin{array}{l}\boldsymbol{p} \\
0.81\end{array}$} \\
\hline Attention and & SCWT & Part I (sec) & & & & \\
\hline \multirow[t]{6}{*}{ functioning } & & Part III (sec) & $26.68 \pm 8.68$ & $28.86 \pm 9.12$ & $26.08 \pm 8.88$ & 0.66 \\
\hline & WCST (64-cards) & Errors & $19.22 \pm 9.64$ & $24 \pm 11.16$ & $19.78 \pm 9.10$ & 0.32 \\
\hline & & Perseverative errors & $9.79 \pm 6.18$ & $12.91 \pm 7.71$ & $10.22 \pm 5.57$ & 0.31 \\
\hline & & Categories* & $2.83 \pm 1.27$ & $2.36 \pm 1.80$ & $2.72 \pm 1.30$ & 0.57 \\
\hline & Digits (WAIS-R) & Forward (DF) & $6.45 \pm 1.97$ & $4.36 \pm 2.33$ & $6.63 \pm 2.51$ & $0.01 *$ \\
\hline & & Backward (DB) & $4.78 \pm 1.58$ & $4.27 \pm 1.49$ & $6.25 \pm 2.36$ & $0.00^{*}$ \\
\hline
\end{tabular}

$C D I$, cocaine-dependent individuals; $C D I+A D H D$, cocaine-dependent individuals with attention deficit/hyperactivity disorder; $S D, S t a n d a r d ~ D e v i a t i o n ~[ \pm] ; S C W T$, Stroop Color Word Test; sec, seconds; WCST, Wisconsin Card Sorting Test; WAIS-R, Wechsler Adult Intelligence Scale-Revised; * $p<0.05-$ statistically significant; $p$ values were calculated using ANOVA.

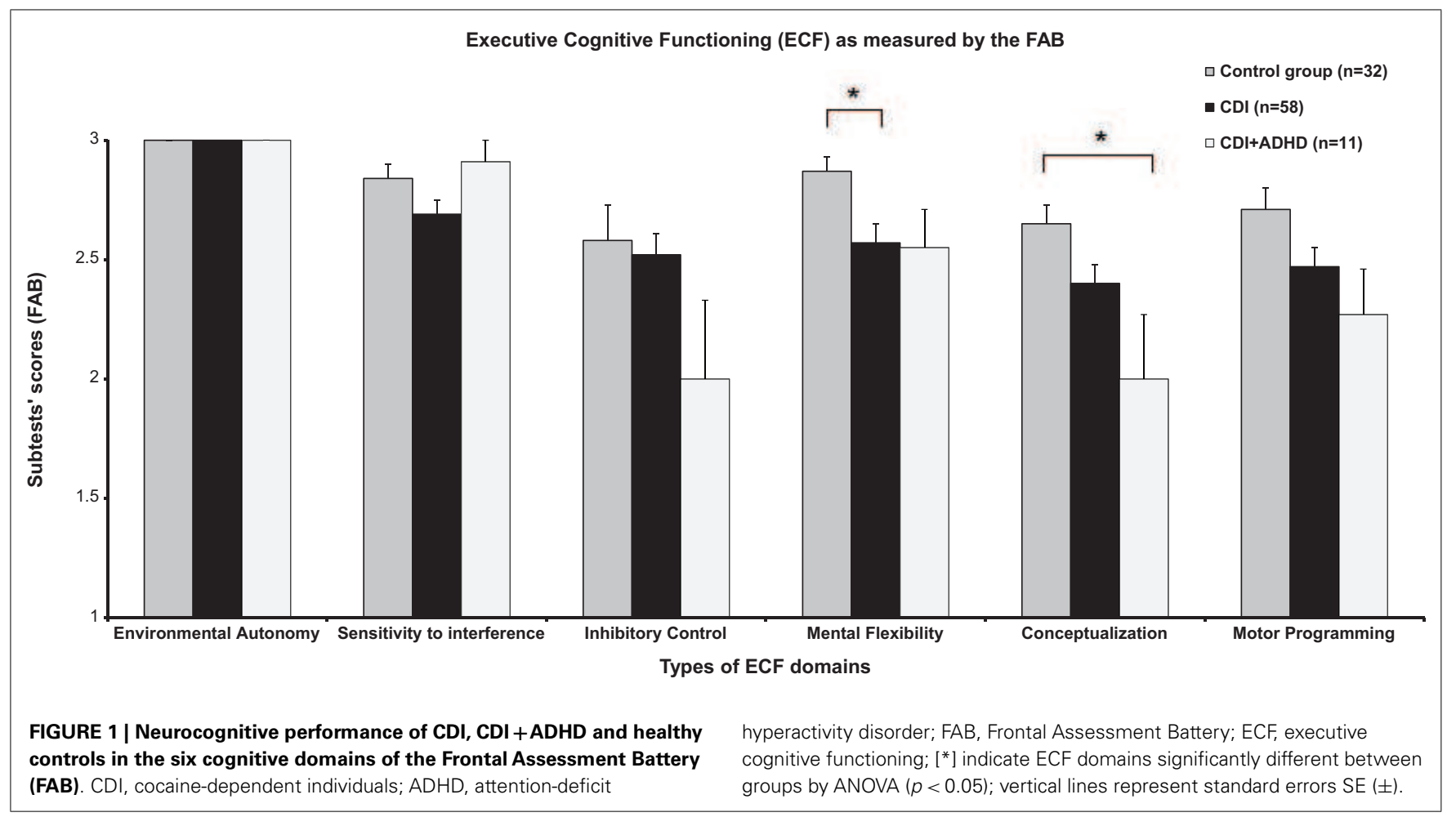

controls $(\mathrm{CDI}+\mathrm{ADHD} \times$ Controls, $p=0.008$; CDI $\times$ Controls, $p=0.001)$.

We also found statistically significant differences in FAB's Conceptualization $(F=4.635, p=0.012)$, FAB's Mental flexibility $(F=3.678, p=0.029)$ and in the total score of the FAB $(F=7.992, p=0.001)$. Post hoc analyses showed that the significant difference in Conceptualization was due to a worse performance of $\mathrm{CDI}+\mathrm{ADHD}$ when directly compared with the normal controls $(p=0.010)$. Difference detected in Mental Flexibility by ANOVA was associated with a lowered performance of CDI compared to controls ( $p=0.029$, Figure 1). Finally, differences among groups in the total's FAB's score were related to a worse performance of both group of patients (CDI and $\mathrm{CDI}+\mathrm{ADHD})$ when directly and separately compared with controls $(\mathrm{CDI}+\mathrm{ADHD} \times$ Controls, $p=0.001$; CDI $\times$ Controls, $p=0.010)$.

CORRELATIONS OF COCAINE-USE VARIABLES AND CHILDHOOD ADHD SCORES BY THE WURS WITH MEASURES OF EXECUTIVE FUNCTIONING

Associative analyses were conducted in order to investigate the influence of the following variables associated with cocaine-use and childhood ADHD symptoms on executive functioning: age at onset of cocaine-use, duration of cocaine-use (in years), length of abstinence from cocaine (in days), and WURS total scores. 
Table 4 | Correlation between drug use variables, childhood ADHD, and neuropsychological measures among the $\mathrm{CDI}$ and $\mathrm{CDI}+\mathrm{ADHD}$.

\begin{tabular}{lllll}
\hline Correlation $\left(\boldsymbol{r}_{\mathbf{s}}\right)$ & $\begin{array}{l}\text { Cocaine } \\
\text { age at } \\
\text { onset } \\
\text { (years) }\end{array}$ & $\begin{array}{l}\text { Cocaine } \\
\text { lifetime } \\
\text { use } \\
\text { (years) }\end{array}$ & $\begin{array}{l}\text { Cocaine } \\
\text { abstinence } \\
\text { length } \\
\text { (days) }\end{array}$ & $\begin{array}{l}\text { Childhood } \\
\text { ADHD } \\
\text { (WURS) }\end{array}$ \\
\hline \multicolumn{2}{l}{ NEUROPSYCHOLOGICAL MEASURES } & & \\
\hline FAB'S total score & 0.016 & 0.015 & -0.078 & $-0.285^{*}$ \\
DF(WAIS-R) & 0.138 & 0.015 & -0.001 & $-0.286^{*}$ \\
DB (WAIS-R) & 0.045 & -0.215 & 0.145 & -0.014
\end{tabular}

$C D I$, cocaine-dependent individuals; $C D I+A D H D$, cocaine-dependent individuals with attention deficit/hyperactivity disorder; $r_{s}$, Spearman correlation coefficient; $F A B$, Frontal Assessment Battery; DF, digits forward; DB, digits backward; WURS, Wender-Utah Rating Scale; correlations were considered statistically significant if ${ }^{*} p<0.05$.

Variables regarding cocaine-use were not correlated with executive functioning in this study. We found a significant negative association between childhood ADHD symptoms as measured by WURS and DF $\left(r_{s}=-0.286 ; p=0.016\right)$ and WURS with the FAB total score $\left(r_{\mathrm{s}}=-0.285 ; p=0.017\right)$. Correlations were analyzed considering both groups of patients together (CDI and CDI + ADHD) (Table 4).

Additionally, considering the differences between samples, between-group analysis of cognitive functioning was conducted using Analysis of Covariance (ANCOVA) with age and gender as covariates, and the results described above remained significant $(p<0.05)$.

\section{DISCUSSION}

In this study, we evaluated CDI with and without a diagnosis of ADHD, and compared them with healthy individuals. Our data confirmed our previous studies $(16,17)$ indicating a poor executive functioning in CDI when compared with normal controls, especially in a brief neuropsychological battery devised for evaluation of prefrontal functioning (FAB) (17). Moreover, a previous diagnosis of $\mathrm{ADHD}$ among $\mathrm{CDI}(\mathrm{CDI}+\mathrm{ADHD})$ was associated with a more pronounced negative impact on executive dysfunction, especially in tasks requiring attentional spam and abstraction ability (concept formation). Our correlation analysis showed consistency of these findings, since the self-reported presence of childhood symptoms of ADHD was negatively associated with actual measures of attention and executive functions. Our findings confirm that $\mathrm{ADHD}$ symptoms have aggravating effects in executive impairments in CDI and also suggest that the pre-existence of executive deficits (suggested by self-reported ADHD symptoms in the childhood) may represent risk factors for a more intense degree of cognitive impairment. Also, even CDI without ADHD presented significant executive impairments, when compared with controls, so cocaine per se may negatively interfere in brain functioning and executive functioning.

The ECF deficits observed in CDI, in general, could support the lack of self-control and persistence of compulsive behavior regarding cocaine-use, despite of the adverse consequences on health and social functioning $(18,52,53)$. In other words, the inability to change a previous behavior (mental flexibility deficits) and the difficulty to acquire and maintain a healthier life-style (conceptualization and working memory deficits) might lead to social dysfunction, treatment drop-outs, and relapses, which are often observed in this population (18, 21-23).

Our findings support the idea that ADHD-related executive dysfunction may represent a predisposing factor, which is brought about by either genetic factors, or early environmental factors (e.g., emotional stress), which may negatively impact the normal development of the PFC, which in turn leads to poor decision-making, which heightens the risk for acquiring addictive disorders (18). The literature is consistent with the hypothesis that ADHD play a powerful role in increasing the likelihood of cocaine and other substance abuse. ADHD symptoms could represent a critical risk factor for cocaine-induced changes of the dopaminergic system and brain alterations (54). The intermittent dopamine stimulation that follows cocaine-use produces acute changes in the synapses and in dopaminergic neurons in the PFC via the striatothalamo-frontal circuit associated with pleasure and reward (55). In the long-term, cocaine-use may cause structural and functional impairments in certain brain areas, including the $\operatorname{PFC}(4,5,52,53)$, representing an additional negative impact on PFC functioning in these subjects $(5,18,56)$.

In other words, while ADHD symptoms since the childhood among cocaine abusers have been considered confounding factors for the neuropsychological evaluation, since ADHD per se is associated to neuropsychological deficits affecting predominantly ECF, ADHD-related symptoms may be an explaining suggestive factor for the future development of cocaine dependence. Much more than a "confounding factor," ADHD might be an "explaining factor" for the understanding of possible cognitive endophenotypes associated with cocaine dependence. It is possible that $\mathrm{CDI}+\mathrm{ADHD}$ would represent a subgroup of patients whose cocaine-use may be associated with a certain type of "selftreatment" for pre-existing ADHD symptoms (32). Also, it is possible that another "subgroup" of CDI would present subclinical ADHD symptoms (as they did not achieve the cutoff score in WURS for ADHD, on the other side symptoms of ADHD in CDI were two times more intense when compared with the control group, $p=0.005)$, to which similar pharmacological and behavioral strategies used for ADHD could be beneficial. For example, a recent study showed that oral methylphenidate $(\mathrm{MPH}$, which is a traditional pharmacological treatment for $\mathrm{ADHD}$ ) may induce better performance (reducing errors) on the SCWT leading to a more careful responding by reducing brain activity in the dorsolateral PFC of CDI as measured by fMRI (57). The authors argued that MPH modulates dopamine in the PFC for both CDI and controls, leading to a better error-related processing, with an effect that is more significant in CDI (57). For CDI + ADHD, the use of oral MPH could be very beneficial, considering that MPH-elicited dopamine increases may improve ADHD symptoms and ventral striatum functioning in adults with ADHD (58). In addition, it could be also relevant to measure the role of other pharmacological treatments, such as mood stabilizers to treat impulsivity and risky behaviors in CDI + ADHD, CDI, and in other addicted patients (59-61). The use of an indicated pharmacological treatment for them could be beneficial, in order to help them to stop cocaine-use 
that may worsen a previous existent executive function deficit. The abuse potential of each pharmacological treatment, however, is an issue that should always be taken into account (61). Also, early detection and treatment of ADHD in children seems to reduce the risk for a later substance-use disorder (SUD) (62).

Other studies have suggested ECF deficits as possible cognitive endophenotypes to addictive disorders (29, 63-65). Healthy adults with family history of alcohol dependence presented more ECF deficits, impulsivity traits (64), and also abnormal brain response during a verbal working memory task (63) than individuals without alcoholics in their families. A similar result was observed in unaffected siblings of stimulants (cocaine and amphetamine) dependents, which exhibited significantly lower ECF and response control than healthy controls (66). After review the findings from high-risk research, problem gamblers, and genetic association studies, Verdejo-García et al. (67) concluded that impulsivity is a pre-existing vulnerability marker for SUDs. In fact, not only impulsivity, but also risk-taking and stress responsivity (68) could be cognitive and behavioral traits guided by genetic factors, constructed under certain environmental influences, which could represent relevant factors on the vulnerability to addictive disorders.

However, some limitations of this study need to be highlighted. First, the present study included a small sample of CDI + ADHD, but we have to bear in mind that our rigidity on criteria for the diagnosis of ADHD was more appropriated to direct our analysis. Second, since the present data are cross-sectional, it was not possible to determine whether self-reported ADHD childhood symptoms detected by WURS indeed afford a reliable method for measuring ECF impairments in the childhood. On the other hand, recent studies have shown that retrospective information provided by adults with ADHD has agreement with parents' reports (69). Also, our correlation analysis indicated a direct link between previous ADHD symptoms and the actual executive dysfunction, suggesting that our data are in consonance with findings that suggest an aggravating effect of ADHD symptoms on cognitive dysfunction (19), but further prospective studies should better investigate our hypothesis. Third, we evaluated samples

\section{REFERENCES}

1. Volkow ND, Mullani N, Gould KL, Adler S, Krajewski K. Cerebral blood flow in chronic cocaine users: a study with positron emission tomography. $\mathrm{Br} J$ Psychiatry (1988) 152:641-8. doi:10.1192/bjp. 152.5.641

2. Volkow ND, Fowler JS, Wolf AP, Hitzemann R, Dewey S, Bendriem $\mathrm{B}$, et al. Changes in brain glucose metabolism in cocaine dependence and withdrawal. Am J Psychiatry (1991) 148(5):621-6.

3. Nicastri S, Buchpiguel CA, Andrade AG. Anormalidades de fluxo sangüíneo cerebral em indivíduos dependentes de cocaína. Rev Bras Psiquiatr (2000) 22(2):42-50. doi:10.1590/S151644462000000200003

with different ages and genders, but the results remained significant when including age and gender as covariates in all analysis. Fourth, alcohol dependence was not an exclusion criteria and we have previously suggested that alcohol use may be associated with frontal lobes impairments (50), but it is unlikely that this may have biased our results because we found a similar proportion of patients with recent alcohol use in CDI and CDI + ADHD. We believe that addicted patients independent of the used drug could have different severities of frontal lobe functions, different ADHD disturbances and different temperaments, so they need specific treatment aims and different treatment strategies. Fifth, it was not possible to determine the reversibility of executive deficits, because the abstinence period in our sample was too short, so future studies should investigate if executive dysfunction in $\mathrm{CDI}+\mathrm{ADHD}$ and CDI could be reversible during cocaine prolonged abstinence.

In summary, our data confirms that $\mathrm{CDI}+\mathrm{ADHD}$ have more pronounced neuropsychological alterations than CDI and controls. Correlation analysis suggested that a possible pre-existing executive dysfunction in CDI + ADHD could lead to a more salient pattern of cognitive impairment and that it is a relevant candidate to a possible cognitive endophenotype of cocaine dependence that influences on later neuropsychological functioning. It remains to be investigated by prospective studies if pre-morbid ECF-related alterations would represent commonalities among the other substance or behavioral addictive disorders (i.e., gambling, sexual compulsive behavior, among others) as well as their genetic and neuroimaging underpinnings.

\section{ACKNOWLEDGMENTS}

This study was funded in part by The State of São Paulo Research Foundation - Brazil (FAPESP) Grants: FAPESP No. 2000/120815 (Dr. Sergio Nicastri, M.D., Ph.D.), FAPESP No. 2010/15.786-1 (Dr. Geraldo F. Busatto), FAPESP No. 2010/15.604-0 (Dr. Paulo Jannuzzi Cunha), and by CNPq - Grant No. 402721/2010-1 (Dr. Geraldo F. Busatto). The authors would also like to thank Dr. Adam J. Sargeant, to APOT (Laura Fracasso, Psy), and to all GREA's and LIM-21's staff.

J, Mehringer CM, et al. Cerebral perfusion and neuropsychological consequences of chronic cocaine use. J Neuropsychiatry Clin Neurosci (1993) 5(4):419-27.

7. Gottschalk C, Beauvais J, Hart R, Kosten T. Cognitive function and cerebral perfusion during cocaine abstinence. Am J Psychiatry (2001) 158(4):540-5. doi:10.1176/appi.ajp. 158.4 .540

8. Tomasi D, Goldstein RZ, Telang F, Maloney T, Alia-Klein N, Caparelli EC, et al. Widespread disruption in brain activation patterns to a working memory task during cocaine abstinence. Brain Res (2007) 1171:83-92. doi:10.1016/j. brainres.2007.06.102

9. Kalivas PW. Glutamate systems in cocaine addiction. Curr Opin
Pharmacol (2004) 4(1):23-9. doi:10. 1016/j.coph.2003.11.002

10. Volkow ND, Fowler JS, Wang GJ, Baler R, Telang F. Imaging dopamine's role in drug abuse and addiction. Neuropharmacology (2009) 56(Suppl 1):3-8. doi:10. 1016/j.neuropharm.2008.05.022

11. Chang L, Ernst T, Strickland T, Mehringer CM. Gender effects on persistent cerebral metabolite changes in the frontal lobes of abstinent cocaine users. Am J Psychiatry (1999) 156(5):716-22.

12. Matochik JA, London ED, Eldreth DA, Cadet JL, Bolla KI. Frontal cortical tissue composition in abstinent cocaine abusers: a magnetic resonance imaging study. Neuroimage (2003) 19(3):1095-102. doi:10. 1016/S1053-8119(03)00244- 1 
13. Moreno-López L, Catena A, Fernández-Serrano MJ, DelgadoRico E, Stamatakis EA, Pérez-García $\mathrm{M}$, et al. Trait impulsivity and prefrontal gray matter reductions in cocaine dependent individuals. Drug Alcohol Depend (2012) 125(3):208-14. doi:10.1016/j. drugalcdep.2012.02.012

14. O’Malley S, Adamse M, Heaton RK, Gawin FH. Neuropsychological impairment in chronic cocaine abusers. Am J Drug Alcohol Abuse (1992) 18(2):131-44. doi:10.3109/ 00952999208992826

15. Gillen RW, Kranzler HR, Bauer LO, Burleson JA, Samarel D, Morrison DJ. Neuropsychologic findings in cocaine-dependent outpatients. Prog Neuropsychopharmacol Biol Psychiatry (1998) 22(7):1061-76. doi:10.1016/S0278-5846(98) 00057-8

16. Cunha PJ, Nicastri S, Gomes LP, Moino RM, Peluso MA. Neuropsychological impairments in crack cocaine-dependent inpatients: preliminary findings. Rev Bras Psiquiatr (2004) 26(2):103-6. doi:10.1590/S151644462004000200007

17. Cunha PJ, Nicastri S, de Andrade AG, Bolla KI. The frontal assessment battery (FAB) reveals neurocognitive dysfunction in substancedependent individuals in distinct executive domains: abstract reasoning, motor programming, and cognitive flexibility. Addict Behav (2010) 35(10):875-81. doi:10.1016/ j.addbeh.2010.05.005

18. Cunha PJ, Bechara A, de Andrade AG, Nicastri S. Decision-making deficits linked to real-life social dysfunction in crack cocainedependent individuals. $A m J$ Addict. (2011) 20(1):78-86. doi:10.1111/j.1521-0391.2010. 00097.x

19. Vonmoos M, Hulka LM, Preller $\mathrm{KH}$, Jenni D, Baumgartner MR, Stohler R, et al. Cognitive dysfunctions in recreational and dependent cocaine users: role of attentiondeficit hyperactivity disorder, craving and early age at onset. $\mathrm{Br} J \mathrm{Psy}$ chiatry (2013) 203(1):35-43. doi: 10.1192/bjp.bp.112.118091

20. Dubois B, Slachevsky A, Litvan I, Pillon B. The FAB: a frontal assessment battery at bedside. Neurology (2000) 55:1621-6. doi:10.1212/ WNL.55.11.1621

21. Aharonovich E, Hasin DS, Brooks AC, Liu X, Bisaga A, Nunes EV. Cognitive deficits predict low treatment retention in cocaine dependent patients. Drug Alcohol Depend
(2006) 81:313-22. doi:10.1016/j. drugalcdep.2005.08.003

22. Verdejo-García A, BetanzosEspinosa P, Lozano OM, VergaraMoragues E, González-Saiz F, Fernández-Calderón F, et al. Selfregulation and treatment retention in cocaine dependent individuals: a longitudinal study. Drug Alcohol Depend (2012) 122(1-2):142-8. doi:10.1016/j.drugalcdep.2011.09. 025

23. Aharonovich E, Nunes E, Hasin D. Cognitive impairment, retention and abstinence among cocaine abusers in cognitive-behavioral treatment. Drug Alcohol Depend (2003) 71(2):207-11. doi:10.1016/ S0376-8716(03)00092-9

24. Dolan SL, Bechara A, Nathan PE. Executive dysfunction as a risk marker for substance abuse: the role of impulsive personality traits. Behav Sci Law (2008) 26(6):799-822. doi:10.1002/bsl.845

25. Glass JM, Buu A, Adams KM, Nigg JT, Puttler LI, Jester JM, et al. Effects of alcoholism severity and smoking on executive neurocognitive function. Addiction (2009) 104(1):38-48. doi:10.1111/j.13600443.2008.02415.x

26. Verdejo-García A, Bechara A, Recknor EC, Perez-Garcia M. Executive dysfunction in substance dependent individuals during drug use and abstinence: an examination of the behavioral cognitive and emotional correlates of addiction. J Int Neuropsychol Soc (2006) 12:405-15.

27. Fillmore MT, Rush CR. Impaired inhibitory control of behavior in chronic cocaine users. Drug Alcohol Depend (2002) 66(3):265-73. doi: 10.1016/S0376-8716(01)00206-X

28. Robinson ES, Eagle DM, Economidou D, Theobald DE, Mar AC, Murphy ER, et al. Behavioural characterisation of high impulsivity on the 5-choice serial reaction time task: specific deficits in 'waiting' versus 'stopping. Behav Brain Res (2009) 196(2):310-6. doi:10.1016/j. bbr.2008.09.021

29. Ersche KD, Turton AJ, Pradhan S, Bullmore ET, Robbins TW. Drug addiction endophenotypes: impulsive versus sensation-seeking personality traits. Biol Psychiatry (2010) 68(8):770-3. doi:10.1016/j. biopsych.2010.06.015

30. Robbins TW, Gillan CM, Smith DG, de Wit S, Ersche KD. Neurocognitive endophenotypes of impulsivity and compulsivity: towards dimensional psychiatry. Trends Cogn Sci (2012) 16(1):81-91. doi:10.1016/j. tics.2011.11.009
31. American Psychiatric Association. Diagnostic and Statistical Manual of Mental Disorders, 4th edition - Text Revised. Washington, DC: American Psychiatric Association Press (2000).

32. Rounsaville BJ, Anton SF, Carroll K, Budde D, Prusoff BA, Gawin F. Psychiatric diagnoses of treatment-seeking cocaine abusers. Arch Gen Psychiatry (1991) 48(1):43-51. doi:10.1001/archpsyc. 1991.01810250045005

33. Seidman LJ, Biederman J, Weber W, Hatch M, Faraone SV. Neuropsychological function in adults with attention-deficit hyperactivity disorder. Biol Psychiatry (1998) 44(4):260-8. doi:10.1016/S00063223(97)00392-2

34. Shallice T, Marzocchi GM, Coser S, Del Savio M, Meuter RF, Rumiati RI. Executive function profile of children with attention deficit hyperactivity disorder. Dev Neuropsychol (2002) 21(1): 43-71. doi:10.1207/ S15326942DN2101_3

35. Tseng WL, Gau SS. Executive function as a mediator in the link between attentiondeficit/hyperactivity disorder and social problems. J Child Psychol Psychiatry (2013) 54(9):996-1004. doi:10.1111/jcpp.12072

36. Slaats-Willemse D, SwaabBarneveld $\mathrm{H}$, de Sonneville L, van der Meulen E, Buitelaar J. Deficient response inhibition as a cognitive endophenotype of ADHD. I Am Acad Child Adolesc Psychiatry (2003) 42(10):1242-8. doi:10.1097/00004583-20031000000016

37. Horner MD. Attentional functioning in abstinent cocaine abusers. Drug Alcohol Depend (1999) 54:19-33. doi:10.1016/S03768716(98)00141-0

38. Beatty WW, Katzung VM, Moreland VJ, Nixon SJ. Neuropsychological performance of recently abstinent alcoholics and cocaine abusers. Drug Alcohol Depend (1995) 37(3):247-53. doi:10.1016/03768716(94)01072-S

39. Woicik PA, Moeller SJ, AliaKlein N, Maloney $\mathrm{T}$, Lukasik TM, Yeliosof $\mathrm{O}$, et al. The neuropsychology of cocaine addiction: recent cocaine use masks impairment. Neuropsychopharmacology (2009) 34(5):1112-22. doi:10.1038/npp.2008.60

40. Beck AT, Ward CH, Mendelson $\mathrm{M}$, Mock J, Erbaugh J. An inventory for measuring depression. Arch Gen Psychiatry (1961)
4:561-71. doi:10.1001/archpsyc 1961.01710120031004

41. Spielberger CD, Gorsuch RL, Lushene RE. Manual for the StateTrait Anxiety Inventory. Palo Alto, CA: Consulting Psychologist Press (1970).

42. Washton AM. Cocaine Addiction: Treatment, Recovery and Relapse Prevention. New York, NY: WW Norton \& Company (1989).

43. McLellan AT, Kushner H, Metzger D, Peters R, Smith I, Grissom $G$, et al. The fifth edition of the addiction severity index. J Subst Abuse Treat (1992) 9:199-213. doi: 10.1016/0740-5472(92)90062-S

44. Wechsler D. Wechsler Intelligence Scale for Adults-Revised (WAIS-R). New York, NY: The Psychological Corporation (1981).

45. Lezak MD, Howieson DB, Loring DW. Neuropsychological Assessment. 4th ed. New York, NY: Oxford University Press (2004).

46. Stroop JR. Studies of interference in serial verbal reaction. J Exp Psychol (1935) 18:643-62. doi:10.1037/ h0054651

47. Heaton RK, Chelune GJ, Talley JL, Kay GG, Curtiss G. Wisconsin Card Sorting Test (WCST) - Manual Revised and Expanded. Odessa, FL: Psychological Assessment Resources (1993).

48. Haaland KY, Vranes LF, Goodwin JS, Garry PJ. Wisconsin Card Sort Test performance in a healthy elderly population. $J$ Gerontol (1987) 42(3):345-6. doi:10.1093/geronj/42.3.345

49. Cunha JA, Trentini CM, Argimon IL, Oliveira MS, Werlang BG, Prieb PG. Teste Wisconsin de Classificação de Cartas. São Paulo: Casa do Psicólogo (2004).

50. Cunha PJ, Novaes MA. Neurocognitive assessment in alcohol abuse and dependence: implications for treatment. Rev Bras Psiquiatr (2004) 26(Suppl 1):S23-7. doi:10.1590/ S1516-44462004000500007

51. Ward MF, Wender PH, Reimherr FW. The Wender Utah Rating Scale: an aid in the retrospective diagnosis of childhood attention deficit hyperactivity disorder. Am J Psychiatry (1993) 150:885-90.

52. Bolla KI, Eldreth DA, London ED, Kiehl KA, Mouratidis M, Contoreggi $\mathrm{C}$, et al. Orbitofrontal cortex dysfunction in abstinent cocaine abusers performing a decisionmaking task. Neuroimage (2003) 19(3):1085-94. doi:10.1016/S10538119(03)00113-7

53. Goldstein RZ, Volkow ND. Drug addiction and its underlying 
neurobiological basis: neuroimaging evidence for the involvement of the frontal cortex. Am J Psychiatry (2002) 159(10):1642-52. doi:10.1176/appi.ajp.159.10.1642

54. Preller KH, Ingold N, Hulka LM, Vonmoos M, Jenni D, Baumgartner MR, et al. Increased sensorimotor gating in recreational and dependent cocaine users is modulated by craving and attention-deficit/hyperactivity disorder symptoms. Biol Psychiatry (2013) 73(3):225-34. doi:10.1016/j.biopsych.2012.08.003

55. Volkow ND, Fowler JS. Addiction, a disease of compulsion and drive: involvement of the orbitofrontal cortex. Cereb Cortex (2000) 10:318-25. doi:10.1093/ cercor/10.3.318

56. Dalley JW, Everitt BJ, Robbins TW. Impulsivity, compulsivity, and top-down cognitive-control. $\mathrm{Neu}$ ron (2011) 69(4):680-94. doi:10. 1016/j.neuron.2011.01.020

57. Moeller SJ, Honorio J, Tomasi D, Parvaz MA, Woicik PA, Volkow ND, et al. Methylphenidate enhances executive function and optimizes prefrontal function in both health and cocaine addiction. Cereb Cortex (2012). doi:10.1093/cercor/bhs345

58. Volkow ND, Wang GJ, Tomasi D, Kollins SH, Wigal TL, Newcorn $\mathrm{JH}$, et al. Methylphenidateelicited dopamine increases in ventral striatum are associated with long-term symptom improvement in adults with attention deficit hyperactivity disorder. I Neurosci
(2012) 32(3):841-9. doi:10.1523/ JNEUROSCI.4461-11.2012

59. Martinotti G, Di Nicola M, Romanelli R, Andreoli S, Pozzi G, Moroni N, et al. High and low dosage oxcarbazepine versus naltrexone for the prevention of relapse in alcohol-dependent patients. Hum Psychopharmacol (2007) 22(3):149-56. doi:10.1002/hup.833

60. Thorens G, Billieux J, Manghi R, Khan R, Khazaal Y, Zullino DF. The potential interest of topiramate in addiction. Curr Pharm Des (2011) 17(14):1410-5. doi:10.2174/ 138161211796150864

61. Martinotti G. Pregabalin in clinical psychiatry and addiction: pros and cons. Expert Opin Investig Drugs (2012) 21(9):1243-5. doi:10.1517/ 13543784.2012.703179

62. Wilens TE, Adamson J, Monuteaux MC, Faraone SV, Schillinger M, Westerberg D, et al. Effect of prior stimulant treatment for attention-deficit/hyperactivity disorder on subsequent risk for cigarette smoking and alcohol and drug use disorders in adolescents. Arch Pediatr Adolesc Med (2008) 162(10):916-21. doi:10.1001/archpedi.162.10.916

63. Cservenka A, Herting MM, Nagel BJ. Atypical frontal lobe activity during verbal working memory in youth with a family history of alcoholism. Drug Alcohol Depend (2012) 123(1-3):98-104. doi:10. 1016/j.drugalcdep.2011.10.021

64. Gierski F, Hubsch B, Stefaniak $\mathrm{N}$, Benzerouk F, Cuervo-Lombard
C, Bera-Potelle C, et al. Executive functions in adult offspring of alcohol-dependent probands: toward a cognitive endophenotype? Alcohol Clin Exp Res (2013) 37(Suppl 1):E356-63. doi:10.1111/ j.1530-0277.2012.01903.x

65. Jupp B, Dalley JW. Behavioral endophenotypes of drug addiction: etiological insights from neuroimaging studies. Neuropharmacology (2013). doi:10. 1016/j.neuropharm.2013.05.041

66. Ersche KD, Turton AJ, Chamberlain SR, Müller U, Bullmore ET, Robbins TW. Cognitive dysfunction and anxiousimpulsive personality traits are endophenotypes for drug dependence. Am J Psychiatry (2012) 169(9):926-36. doi:10.1176/appi. ajp.2012.11091421

67. Verdejo-García A, Lawrence AJ, Clark L. Impulsivity as a vulnerability marker for substance-use disorders: review of findings from highrisk research, problem gamblers and genetic association studies. Neurosci Biobehav Rev (2008) 32(4): 777-810. doi:10.1016/j.neubiorev. 2007.11.003

68. Kreek MJ, Nielsen DA, Butelman ER, LaForge KS. Genetic influences on impulsivity, risk taking, stress responsivity and vulnerability to drug abuse and addiction. Nat Neurosci (2005) 8(11):1450-7. doi:10. $1038 / \mathrm{nn} 1583$

69. Dias G, Mattos P, Coutinho G, Segenreich D, Saboya E, Ayrão V. Agreement rates between parent and self-report on past $\mathrm{ADHD}$ symptoms in an adult clinical sample. $J$ Atten Disord (2008) 12(1):70-5. doi:10.1177/108705470731122

Conflict of Interest Statement: The authors declare that the research was conducted in the absence of any commercial or financial relationships that could be construed as a potential conflict of interest.

Received: 01 August 2013; accepted: 24 September 2013; published online: 21 October 2013.

Citation: Cunha PJ, Gonçalves PD, Ometto $M$, dos Santos B, Nicastri S, Busatto GF and de Andrade AG (2013) Executive cognitive dysfunction and $A D H D$ in cocaine dependence: searching for a common cognitive endophenotype for addictive disorders. Front. Psychiatry 4:126. doi: 10.3389/fpsyt.2013.00126

This article was submitted to Addictive Disorders and Behavioral Dyscontrol, a section of the journal Frontiers in Psychiatry.

Copyright (C) 2013 Cunha, Gonçalves, Ometto, dos Santos, Nicastri, Busatto and de Andrade. This is an open-access article distributed under the terms of the Creative Commons Attribution License (CC BY). The use, distribution or reproduction in other forums is permitted, provided the original author(s) or licensor are credited and that the original publication in this journal is cited, in accordance with accepted academic practice. No use, distribution or reproduction is permitted which does not comply with these terms. 